\title{
Long-Term Dietary Folate Deficiency Accelerates Progressive Hearing Loss on CBA/Ca Mice
}

\begin{abstract}
Raquel Martínez-Vega ${ }^{1}$, Silvia Murillo-Cuesta ${ }^{1,2,3}$, Teresa Partearroyo ${ }^{4}$, Gregorio Varela-Moreiras ${ }^{4}$, Isabel Varela-Nieto ${ }^{1,2,3+}$ and María A. Pajares ${ }^{1,3 * t}$
\end{abstract}

\begin{abstract}
${ }^{1}$ Instituto de Investigaciones Biomédicas Alberto Sols (CSIC-UAM), Madrid, Spain, ${ }^{2}$ Unidad 761, Centro de Investigación Biomédica en Red de Enfermedades Raras (CIBERER), Instituto de Salud Carlos III, Madrid, Spain, ${ }^{3}$ Instituto de Investigación Hospital Universitario La Paz (IdiPAZ), Madrid, Spain, ${ }^{4}$ Departamento de Ciencias Farmacéuticas y de la Salud, Facultad de Farmacia, Universidad CEU San Pablo, Madrid, Spain
\end{abstract}

Dietary folic acid deficiency induced early hearing loss in C57BL/6J mice after 2-months, corroborates the epidemiological association previously described between vitamin deficiency and this sensory impairment. However, this strain is prone to early hearing loss, and hence we decided to analyze whether the effects exerted by folate deprivation follow the same pattern in a mouse strain such as CBA/Ca, which is resistant to hearing impairment. Here, we show results of a long-term study on hearing carried out on CBA/Ca mice subjected to dietary folate deprivation. Systemic changes included decreased serum folate levels, hyperhomocysteinemia and signs of anemia in the group fed with folate-deficient (FD) diet. Initial signs of hearing loss were detected in this strain

OPEN ACCESS

Edited by:

Shin Murakami,

Touro University California, USA

Reviewed by:

Ting-Ting Huang, Stanford University, USA Sabarish Ramachandran, Texas Tech University Health Sciences Center, USA

${ }^{*}$ Correspondence: María A. Pajares mapajares@iib.uam.es

tShared senior authorship.

Received: 14 March 2016 Accepted: 18 August 2016 Published: 31 August 2016

Citation: Martínez-Vega R, Murillo-Cuesta S, Partearroyo T, Varela-Moreiras G, Varela-Nieto I and Pajares MA (2016) Long-Term Dietary Folate Deficiency Accelerates Progressive Hearing Loss on CBA/Ca Mice.

Front. Aging Neurosci. 8:209. doi: 10.3389/fnagi.2016.00209 after 8-months of vitamin deficiency, and correlated with histological damage in the cochleae. In conclusion, the data presented reinforce the importance of adequate folic acid levels for the auditory system and suggest that the impact of dietary deficiencies may depend on the genetic background.

Keywords: vitamin deficiency, hearing impairment, homocysteine, cochlea, dietary intervention,
hyperhomocysteinemia, folic acid

\section{INTRODUCTION}

Hearing loss is a sensory impairment caused by genetic and environmental factors (Dror and Avraham, 2009; Roth et al., 2011), whose incidence is increasing according to reports of the World Health Organization. Factors such as noise and ototoxic drugs are well-known effectors of this impairment, but more recently several epidemiological studies have shown the association between the nutritional status and hearing loss. Precisely, inadequate levels of folic acid have been correlated with hearing loss in the presence of reduced vitamin $B_{12}$ concentrations or hyperhomocysteinemia (Houston et al., 1999; Cadoni et al., 2004; Lasisi et al., 2010). Additional reports have explored the putative association of mutations in genes of the folate cycle and the impact of hearing loss, their results being somewhat inconsistent (Durga et al., 2006; Uchida et al., 2011). In contrast, two animal studies have demonstrated the link between homocysteine (Hcy) metabolism and hearing loss (Cohen-Salmon et al., 2007; Martinez-Vega et al., 2015a) and the effects of a folate-deficient (FD) diet in the auditory system (Martinez-Vega et al., 2015a). Thus, remarkable increases in auditory brainstem response (ABR) thresholds were detected in C57BL/6J mice after 2-months on a FD diet (Martinez-Vega et al., 2015a). These changes correlated with the presence of severe histological damage in the cochlea and with important 
alterations in cochlear metabolism. Folate deficiency induced a decrease in Hcy remethylation and its flux through transsulfuration, together with an increase in adenosine elimination, as deduced from the important changes observed in the enzymes involved. Altogether these changes led to cochlear accumulation of Hcy, resulting in enhanced protein homocysteinylation, and in redox stress in FD cochleae (Martinez-Vega et al., 2015a). C57BL/6J is a strain known to develop premature hearing loss, a phenotypic trait that was accelerated in FD mice. Therefore, we set up a new experiment using the $\mathrm{CBA} / \mathrm{Ca}$ mouse strain, less prone to hearing loss, to further evaluate the impact of folate deficiency in the development of this impairment.

\section{MATERIALS AND METHODS}

\section{Mouse Handling and Experimental Design}

Two month-old CBA/Ca female mice were purchased from Harlan Interfauna Ibérica S.A. and housed under standard conditions. Mice were randomly divided into two experimental groups ( $n=10$ each) that were fed the A04/A04C/R04 diet (Panlab/SAFE) containing standard folate levels (normal folate $2 \mathrm{mg} / \mathrm{kg}$; NF) or a FD diet (folic acid $\leq 0.1-0.2 \mathrm{mg} / \mathrm{kg}$, Harlan Tecklad TD.95247) ad libitum for 8 months. Weight gain was measured weekly for both dietary regimes. All experiments were approved by the CSIC Bioethics Committee and carried out in full accordance with the guidelines of the European Community (2010/63/EU) and the Spanish regulations (RD 53/2013).

\section{Blood Analysis and Histology}

Blood samples were collected through the external maxillary vein (2-months of age; $2 \mathrm{M}$ ) or by cardiac puncture after $\mathrm{CO}_{2}$ asphyxiation (10-months of age; $10 \mathrm{M}$ ), and directly placed in either regular or heparin coated tubes (Laboratorios Farmacéuticos Rovi). Isolation of serum and plasma fractions was performed after centrifugation at $2500 \times \mathrm{g}$ for $10 \mathrm{~min}$. The hematological analysis was performed with Abacus Junior Vet 5 automatic equipment (Diatron). Fresh blood (2/mice) extensions were prepared for Wright staining (Reagan et al., 2011).

For histological analysis mice were injected a pentobarbital overdose and perfused with PBS/paraformaldehyde as previously described (Camarero et al., 2001; Sanchez-Calderon et al., 2010), before tissue extraction (cochlea and femur; Rodriguez-de la Rosa et al., 2014). Decalcified samples were dehydrated and embedded in paraffin (Panreac Química), as previously described (Aburto et al., 2012). Cochlear and bone marrow cytoarchitecture was evaluated using representative paraffin sections $(7 \mu \mathrm{m}$ thick) and Nissl or hematoxylin-eosin staining (Reagan et al., 2011).

\section{Hearing Assessment}

Mice were anesthetized with a mixture of ketamine $(100 \mathrm{mg} / \mathrm{kg}$; Imalgene 1000, Merial) and xylazine (10 mg/kg; Rompun $2 \%$, Bayer) for ABR analysis using a Tucker Davis Technologies workstation. The electrical responses to broadband click and
$8,16,20,28$ and $40 \mathrm{kHz}$ pure tone stimuli, with an intensity range $90-20 \mathrm{~dB}$ SPL in 5-10 dB steps, were recorded as previously reported (Cediel et al., 2006; Murillo-Cuesta et al., 2012). The electrical responses were amplified and averaged to determine hearing thresholds for each stimulus. Peak and interpeak latencies were analyzed at 15-20 dB SPL above hearing threshold after click stimulation. Recording of distortion product otoacoustic emissions (DPOAEs) was performed after stimulation with $\mathrm{f} 1$ and $\mathrm{f} 2$ primary tones, with a ratio $\mathrm{f} 2 / \mathrm{f} 1=1.2$ using a $\mathrm{TDT}$ equipment, as described previously (Martinez-Vega et al., 2015b). Primary tones for $8,10,14,18$ and $22 \mathrm{kHz}$ frequencies were tested.

\section{Metabolite Determinations}

Total Hcy (tHcy) was derivatized using the Reagent kit for HPLC analysis of Hcy in plasma/serum (Chromsystems Instruments and Chemicals $\mathrm{GmbH}$, Munich, Germany). The resulting samples $(50 \mu \mathrm{l})$ were then injected into the HPLC column and fluorescence measured at $515 \mathrm{~nm}$ upon excitation at $385 \mathrm{~nm}$.

Total serum folate was determined using the microbiological method developed by Horne and Patterson (1988) with Tamura's modifications (Tamura, 1990).

\section{Statistical Analysis}

Statistical analysis was carried out between NF and FD groups at the specified time points using the Student's $t$-test for unpaired samples was performed with SPSS v 19.0 software package (SPSS, Chicago, IL, USA). No statistical evaluation was performed within each dietary group during the whole experiment.

\section{RESULTS}

The CBA/Ca mouse strain, known to present with late-onset of hearing loss (18-months onward; Li and Borg, 1991; Zheng et al., 1999), was chosen to evaluate the impact of a FD diet during a long-term study carried out for 8 months. No statistical differences in the daily food intake were found between NF and FD groups during the experiment. However, animals in the FD group gained less weight than those on the NF diet, this difference becoming significant at 9-10 months of age (Figure 1A). Nevertheless, both daily ingestion and weight gain remained above normal values for this strain ${ }^{1}$.

Additional effects of the dietary treatment were analyzed in blood samples obtained at the start and the endpoint of the study (Figure 1B). No differences in serum folate levels between groups were detected at the beginning of the experiment (NF-2M vs. FD-2M), whereas a five-fold decrease was measured in the FD-10M group. This decrease correlated with a seven-fold increase in tHcy levels in FD-10M mice (Figure 1B), as expected for the role of folate in Hcy remethylation. Altogether, these systemic metabolic changes confirmed the efficacy of the dietary treatment.

\footnotetext{
${ }^{1}$ http://www.envigo.com/resources/growth-curves/growth-curvecbacaola_505_b2_2013.pdf
} 
A

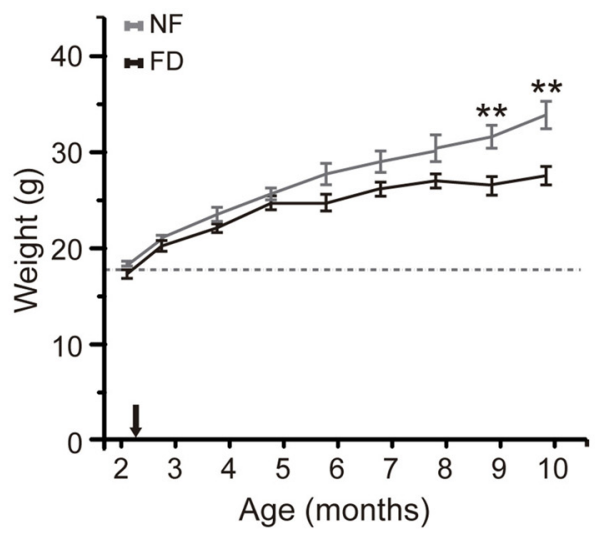

B

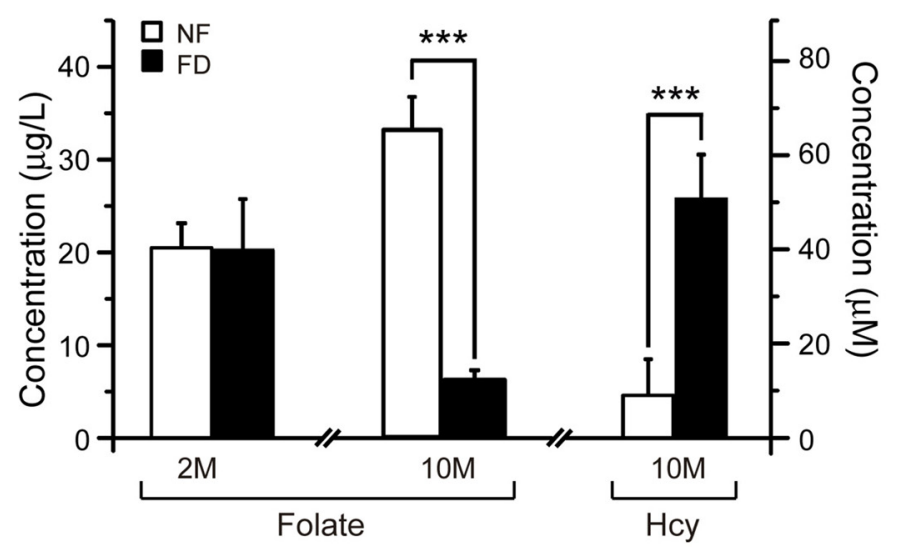

C
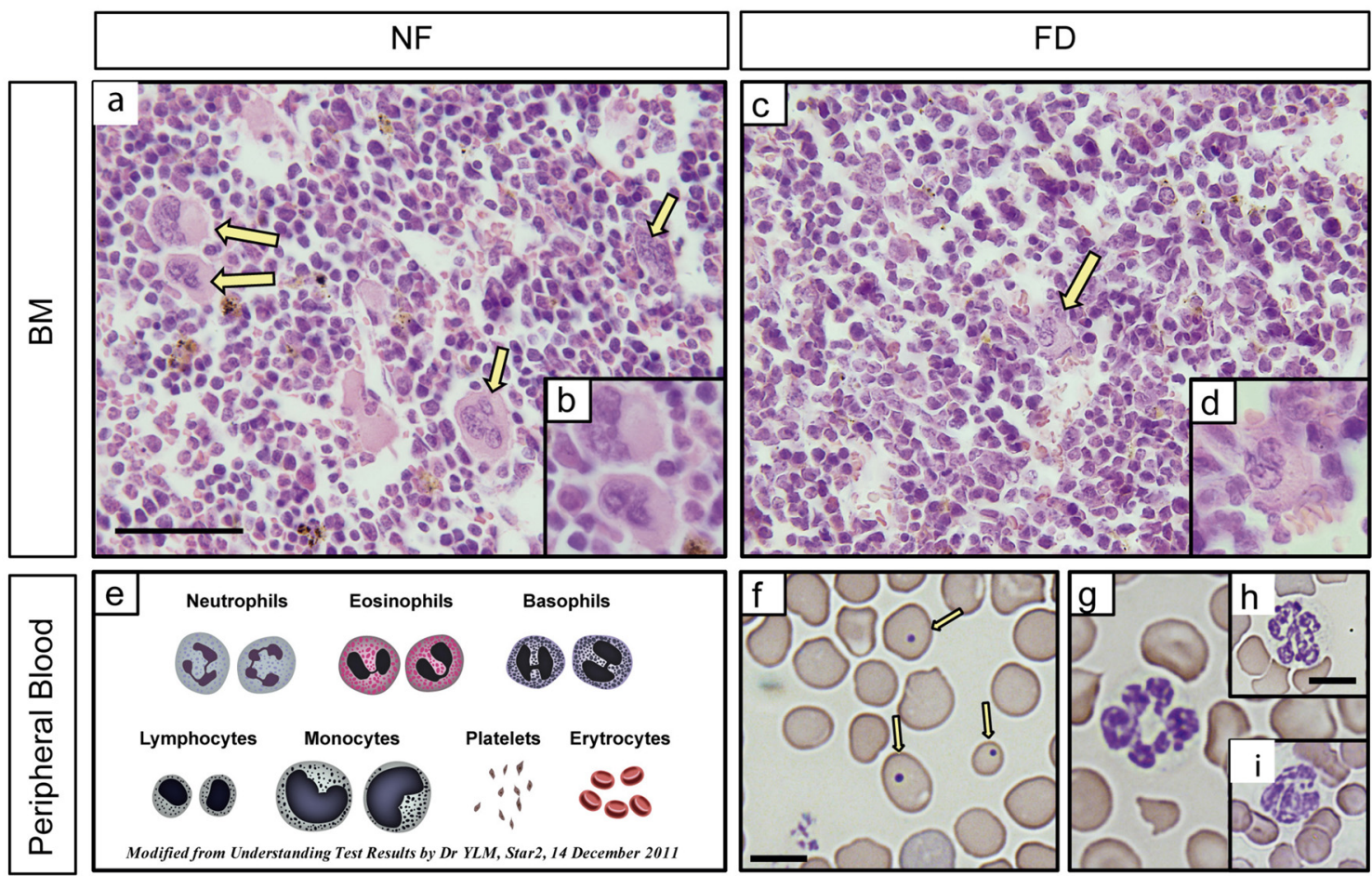

FIGURE 1 | (A) Weight gain along the study. The size of each group is specified in Table 2. Several mice from the folate-deficient (FD) group were sacrificed due to their condition, and hence the group size was reduced $(n=5)$ from 7 months of age onward. (B) Serum folate concentrations were measured at 2-months of age $(2 \mathrm{M})$ in the normal folate (NF; $n=9)$ and FD $(n=5)$ groups. At 10-months (10M) of age serum folate and homocysteine (Hcy) concentrations were determined in the NF $(n=9)$ and FD groups $(n=5)$. (C) Hematoxylin-eosin staining of bone marrow $(\mathbf{a}-\mathbf{d})$ and Wright staining of peripheral blood (f-i) at $10 \mathrm{M}(n=5$ for both dietary groups). Megakaryocytes (yellow arrows), scheme of normal erythrocytes and white series (e), anisocytosis and Howell-Jolly bodies (f, arrows). Bar scale 50 $\mu \mathrm{m}$ (a,c); $25 \mu \mathrm{m}$ (b,d); $10 \mu \mathrm{m}$ (remaining panels). Statistical analysis was performed between NF and FD groups at each of the specified time points; no evaluation within the same dietary groups was performed. ${ }^{* *} p<0.01 ;{ }^{* * *} p<0.001$.

FD-10M mice also presented decreased hemoglobin levels, packed cell volume and hematocrit values, lower red and white blood cell counts and reduced lymphocyte percentage, together with increased mean corpuscular volume, mean corpuscular hemoglobin and an enhanced degree of anisocytosis (Table 1). Their bone marrow showed a decrease in megakaryocyte number, which also had lower differentiation and volume (Figure 1C). Along with these alterations an increased number of Howell-Jolly bodies, hypersegmented polymorphonuclear neutrophils and strong anisocytosis were 
TABLE 1 | Blood parameters of CBA/Ca mice.

\begin{tabular}{|c|c|c|}
\hline & \multicolumn{2}{|c|}{10 months of age } \\
\hline & $\mathrm{NF}^{1}(n=5)$ & $\mathrm{FD}^{1}(n=5)$ \\
\hline White blood cells $\left(10^{9} / \mathrm{L}\right)$ & $6.36 \pm 0.23$ & $3.10 \pm 0.52^{* * *}$ \\
\hline Red blood cells $\left(10^{12} / \mathrm{L}\right)$ & $9.53 \pm 0.12$ & $6.61 \pm 0.30^{* * *}$ \\
\hline Hemoglobin (g/dL) & $14.08 \pm 0.34$ & $11.38 \pm 0.51^{* *}$ \\
\hline Hematocrit (\%) & $46.88 \pm 0.80$ & $38.43 \pm 1.32^{* *}$ \\
\hline Mean corpuscular volume (fL) & $49.50 \pm 0.29$ & $58.25 \pm 0.75^{* * * *}$ \\
\hline $\begin{array}{l}\text { Mean corpuscular hemoglobin } \\
\text { concentration }(\mathrm{g} / \mathrm{dL})\end{array}$ & $30.03 \pm 0.45$ & $29.63 \pm 0.61$ \\
\hline Mean corpuscular hemoglobin (pg) & $14.78 \pm 0.25$ & $17.28 \pm 0.34^{* * *}$ \\
\hline Anisocytosis (\%) & $17.28 \pm 0.28$ & $20.58 \pm 0.54^{* *}$ \\
\hline Granulocytes (\%) & $22.06 \pm 1.01$ & $29.03 \pm 2.35$ \\
\hline Lymphocytes (\%) & $75.65 \pm 1.36$ & $52.53 \pm 7.29^{*}$ \\
\hline Mid-range cells (\%) & $4.60 \pm 1.15$ & $6.43 \pm 1.44$ \\
\hline
\end{tabular}

observed in peripheral blood extensions of FD-10M mice (Figure 1C). Altogether, these changes indicated signs of megaloblastic anemia that jointly with the presence of signs of stress in the FD-10M mice, led to the interruption of our study at $10 \mathrm{M}$, despite the late-onset of $\mathrm{HL}$ described for these mice.

The auditory function was evaluated every month in both dietary groups. No significant changes in ABR threshold, latencies, or amplitudes were evident between NF and FD mice along the whole study (Table 2). Both NF-10M and FD-10M groups showed a decreased amplitude of wave I, which correlated with a slight increase in hearing thresholds. Histological analysis revealed damage in the organ of Corti (OC) at the low basal turn of the cochlea, together with a slight loss in type IV fibrocytes at the spiral ligament (Spl) and accumulation of melanin granules in the stria vascularis ( $\mathrm{StV}$; Figure 2A). Altogether, these alterations are indicative of the initial phases of hearing loss in both dietary groups, but seem more severe in cochleae of FD mice in which the absence of outer hair cells is noticed (Figure 2Ag).

The presence of the $2 f 1-f 2$ component after pure tone stimulation was evident in both groups in DPOAE studies. However, FD-10M mice presented increased DP thresholds at all the frequencies studied as compared to NF-10M mice, the differences being significant at $8-14 \mathrm{kHz}$ (Figure 2B). Concomitantly, decreased $2 f 1-f 2$ amplitude was detected in the FD-10M group, which became significant at $10 \mathrm{kHz}$ (Figure 2Bb). These results suggested that the initial signs of hearing loss and the outer hair cell damage were more pronounced in the FD than in the NF group after 8 months of nutritional intervention.

\section{DISCUSSION}

The relationship between nutritional deficiencies in vitamins, including folate deficiency, and hearing loss has been explored in a variety of epidemiological studies (Houston et al., 1999; Cadoni et al., 2004; Lasisi et al., 2010; Attias et al., 2012; Karli et al., 2013). However, the data obtained have not always been consistent. This fact, led several authors to the evaluation of the putative contribution of human mutations to these disparities and, among them, the analysis of modifications in key genes of the onecarbon metabolism. Evaluation of the relationship between the polymorphism C677T in the methylenetetrahydrofolate

TABLE 2 | Auditory brainstem response (ABR) results at three points of the study.

\begin{tabular}{|c|c|c|c|c|c|c|c|}
\hline & & \multicolumn{6}{|c|}{ Age } \\
\hline & & $\mathrm{NF}(n=9)$ & $\mathrm{FD}(n=10)$ & NF $(n=9)$ & FD $(n=9)$ & NF $(n=9)$ & FD $(n=5)$ \\
\hline \multirow[t]{4}{*}{$\mathrm{ABR}^{1}$ threshold (dB SPL) } & Click & $16 \pm 1$ & $17 \pm 1$ & $16 \pm 1$ & $18 \pm 1$ & $24 \pm 1$ & $24 \pm 3$ \\
\hline & $8 \mathrm{kHz}$ & $22 \pm 1$ & $25 \pm 0$ & $23 \pm 1$ & $23 \pm 1$ & $44 \pm 4$ & $43 \pm 1$ \\
\hline & $16 \mathrm{kHz}$ & $21 \pm 1$ & $25 \pm 2$ & $24 \pm 1$ & $25 \pm 0$ & $43 \pm 5$ & $43 \pm 3$ \\
\hline & $40 \mathrm{kHz}$ & $28 \pm 1$ & $30 \pm 2$ & $32 \pm 1$ & $29 \pm 1$ & $39 \pm 2$ & $38 \pm 1$ \\
\hline \multirow[t]{4}{*}{ Peak latencies ${ }^{1}$ (ms) } & Wave I & $1.42 \pm 0.01$ & $1.33 \pm 0.02$ & $1.29 \pm 0.04$ & $1.35 \pm 0.02$ & $1.39 \pm 0.02$ & $1.34 \pm 0.04$ \\
\hline & Wave II & $2.42 \pm 0.03$ & $2.36 \pm 0.02$ & $2.18 \pm 0.04$ & $2.31 \pm 0.02$ & $2.36 \pm 0.03$ & $2.31 \pm 0.07$ \\
\hline & Wave III & $3.17 \pm 0.04$ & $2.99 \pm 0.05$ & $2.87 \pm 0.06$ & $2.97 \pm 0.03$ & $3.17 \pm 0.06$ & $3.20 \pm 0.09$ \\
\hline & Wave IV & $4.07 \pm 0.03$ & $3.93 \pm 0.04$ & $3.90 \pm 0.05$ & $3.93 \pm 0.02$ & $4.06 \pm 0.03$ & $3.99 \pm 0.04$ \\
\hline \multirow[t]{2}{*}{ Interpeak latencies ${ }^{1}$ (ms) } & $|-| \mid$ & $1.00 \pm 0.02$ & $1.02 \pm 0.01$ & $0.98 \pm 0.02$ & $0.96 \pm 0.01$ & $0.97 \pm 0.02$ & $0.97 \pm 0.03$ \\
\hline & I-IV & $2.65 \pm 0.03$ & $2.60 \pm 0.03$ & $2.61 \pm 0.03$ & $2.58 \pm 0.02$ & $2.68 \pm 0.02$ & $2.65 \pm 0.03$ \\
\hline & Wave IV & $1278 \pm 175$ & $1105 \pm 104$ & $1227 \pm 210$ & $1449 \pm 106$ & $746 \pm 94$ & $797 \pm 129$ \\
\hline
\end{tabular}

Hearing parameters were measured during the whole study in the normal (NF) and folate deficient (FD) dietary groups, although only three key points of the experiment that correspond to the start, 5 and 8 months of diet administration (2, 7 and 10 months of age) are shown. ${ }^{1}$ mean \pm SEM. 
A

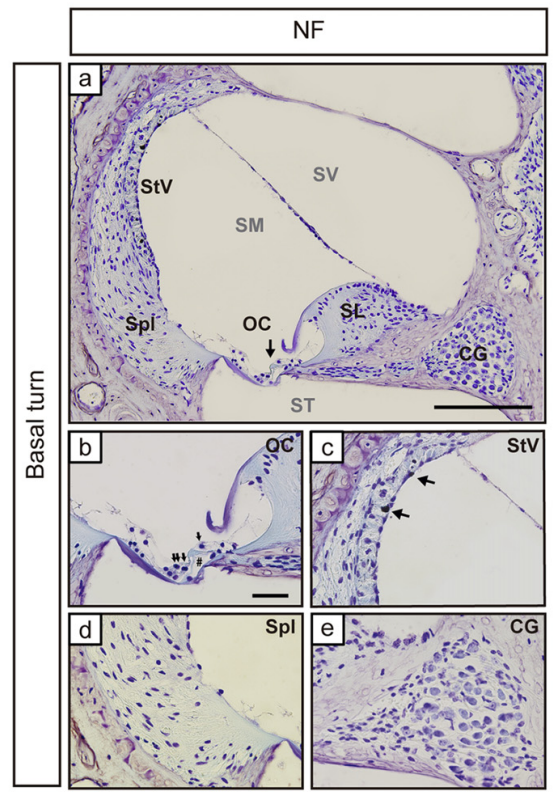

B

a

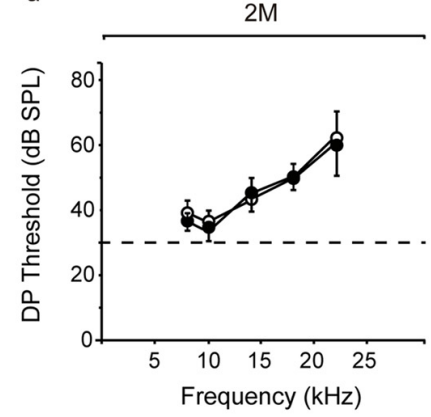

b

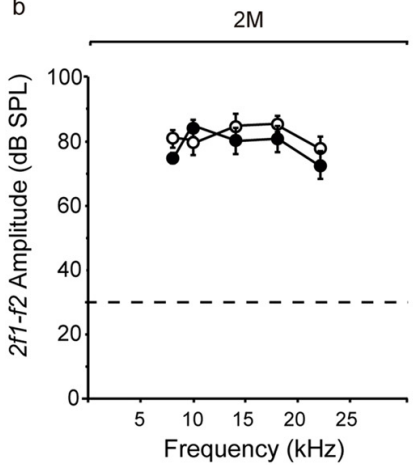

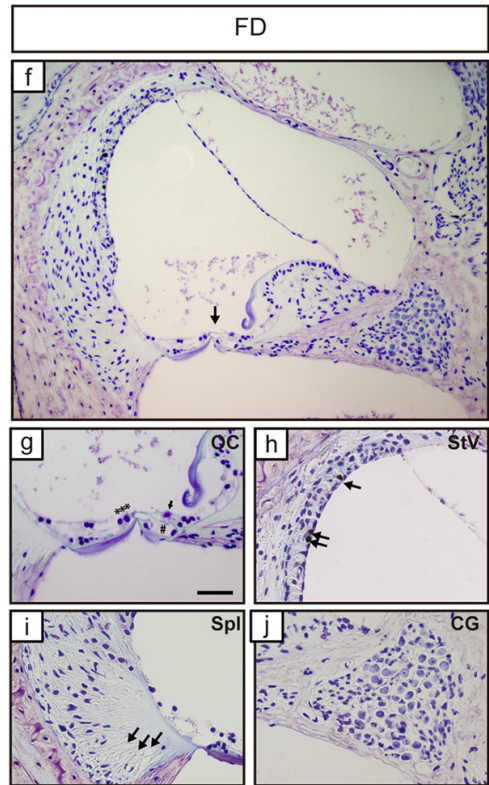

$10 \mathrm{M}$
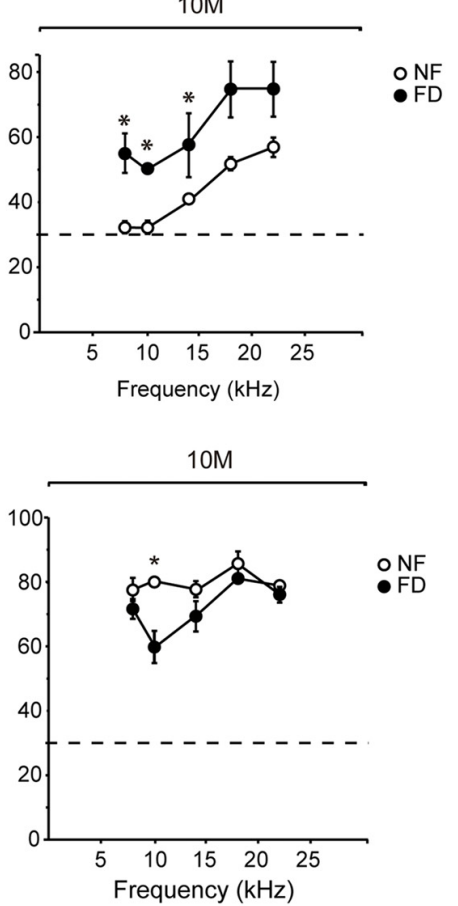

FIGURE 2 | Representative histological images of the Nissl-stained basal regions and distortion product otoacoustic emissions (DPOAE) results. (A) General views of the cochlear basal turn $(\mathbf{a}, \mathbf{f})$ for NF $(n=3)$ and FD mice $(n=3)$ 10-months old. Detailed views of the organ of Corti (OC; $\mathbf{b}, \mathbf{g})$, where collapse of the inner and outer pillar cells is observed in both dietary groups (\#) and the presence of outer hair cells in the NF (arrows) and their absence in the FD group (***) are indicated. Additional subpanels show detailed views of the stria vascularis (StV; c,h) with melanin granules in both dietary groups (arrows); spiral ligament (Spl; d,i) and cochlear ganglion (CG; e,j). Bar scale: $150 \mu \mathrm{m}$ (a,f); $25 \mu \mathrm{m}$ (remaining panels). (B) DPOAE analysis at 2- (2M; NF $n=9$ and FD $n=10)$ and 10-months (10M; $\mathrm{NF} n=9$ and FD $n=5$ ) of age; DP thresholds (a) and 2f1-f2 amplitudes (b) are shown (mean $\pm \mathrm{SEM}$ ). ${ }^{*} p<0.05$.

reductase gene, a key player in folate metabolism, and hearing loss rendered contradictory results (Durga et al., 2006; Uchida et al., 2011; Fusconi et al., 2012). In contrast, animal studies have provided clues to the interplay between folate, Hcy and hearing loss, showing alterations in Hcy metabolism correlating with the onset of this impairment (Cohen-Salmon et al., 2007; Kundu 
et al., 2012; Martinez-Vega et al., 2015a). In this line of evidence, a previous study using the $\mathrm{C} 57 \mathrm{BL} / 6 \mathrm{~J}$ mouse strain, known by its early onset of hearing loss, showed that a decrease in folate intake accelerates development of this sensory decline (Martinez-Vega et al., 2015a). A fact that correlated with a systemic decrease of the vitamin levels and concomitant hyperhomocysteinemia, as expected from the critical role of folate in Hcy remethylation (Pajares and Pérez-Sala, 2006). These systemic changes are also detected in the present study using CBA/Ca mice during long-term feeding with a folate deprived diet, following the same trend than in C57BL/6J mice after 2 months of FD diet (Martinez-Vega et al., 2015a). However, hyperhomocysteinemia was more severe in $\mathrm{CBA} / \mathrm{Ca}$ mice after 8 months on the FD diet than in C57BL/6J mice after 2 months (Martinez-Vega et al., 2015a).

Folate deficiency induced premature signs of hearing loss in both strains, although their appearance is delayed more than 6 months in the CBA/Ca strain as compared to C57BL/6J mice (Martinez-Vega et al., 2015a). Moreover, the extent of the damage is also very different, since most C57BL/6J mice showed profound hearing loss after 2 months on the FD diet (Martinez-Vega et al., 2015a), whereas the changes in hearing parameters in CBA/Ca mice are small, but consistent (increased DP thresholds and 2f1- $f 2$ amplitude) and appear after 8 months on the deficient diet. In fact, histological data corroborated cochlear damage in $\mathrm{CBA} / \mathrm{Ca}$ mice that was more evident in the FD animals. Folate-induced damage seemed restricted to the low basal turn of the cochlea, thus explaining that stimulation required high frequency sounds (Müller et al., 2005). This higher resistance of the CBA/Ca cochleae against vitamin deficiency may rely in differences in the genetic background of the strains used that remain largely unknown (Willott et al., 1995).

The high resistance against FD-induced hearing loss exhibited by CBA/Ca mice, as compared to the C57BL/6J strain used in our previous work (Martinez-Vega et al., 2015a), suggested putative differences in genes involved in folate metabolism. However, the small size of the mouse cochleae and the histological procedures carried out precluded an expression study on the remaining samples. Nevertheless, a search carried out into the Mouse Genome Project database showed a number of single nucleotide polymorphisms (SNPs) on several genes of folate metabolism in $\mathrm{CBA} / \mathrm{J}$ mice as compared to the reference $\mathrm{C} 57 \mathrm{BL} / 6 \mathrm{~J}$ strain (Keane et al., 2011). No differences in Mtr, Bhmt, Dhfr, Tyms, $M t h f d 1$ and $M t h f d 2$ genomic sequences were found between both strains (Table 3). In contrast, several SNPs for Bhmt2, Folr1, Folr2, Mtrr, Mthfr, Shmt1 and Shmt2 were identified. Among them, a missense mutation on Folrl for which the functional impact remains unknown, and those on Bhmt2, a gene whose hepatic expression levels have been proposed as a dietary-dependent factor conferring protection against drug intoxication (Liu et al., 2010). In this work, Liu et al. (2010) suggested that strains with higher hepatic BHMT2 levels/activity would be adapted for a lower dependence on folate for Hcy recycling by the use of S-methylmethionine as methyl donor. Clarification on whether this postulate is valid for the auditory system would require an extensive work on genomic sequencing
TABLE 3 | Single nucleotide polymorphisms (SNPs) for key genes of folate metabolism detected in CBA/J mice according to the Mouse Genome Project.

\begin{tabular}{|c|c|c|c|c|}
\hline Gene & $\begin{array}{l}\text { Base in } \\
\text { C57BL/6J }\end{array}$ & SNP & $\begin{array}{l}\text { Base in } \\
\text { CBA/J }\end{array}$ & Main change \\
\hline \multirow[t]{11}{*}{ Folr1 } & $G$ & rs477388978 & $A^{*}$ & 3'-UTR \\
\hline & A & rs47631647 & $G^{*}$ & missense F236L \\
\hline & $\mathrm{G}$ & rs47445319 & $A^{*}$ & upstream 2KB \\
\hline & A & rs49747152 & $G^{*}$ & upstream 2KB \\
\hline & C & rs50854846 & A & intron \\
\hline & C & rs52411810 & A & intron \\
\hline & A & rs586270005 & $\mathrm{T}$ & intron \\
\hline & C & rs52321323 & $\mathrm{T}$ & intron \\
\hline & C & rs52448898 & $A^{*}$ & upstream 2KB \\
\hline & $G$ & rs240085681 & C & intron \\
\hline & G & rs262701625 & A & intron \\
\hline \multirow[t]{4}{*}{ Folr2 } & C & rs32160123 & $\mathrm{G}^{*}$ & intron \\
\hline & C & rs31011801 & $\mathrm{T}^{*}$ & intron \\
\hline & $A$ & rs31275071 & $\mathrm{C}^{*}$ & intron \\
\hline & $\mathrm{T}$ & rs48667177 & $A^{*}$ & intron \\
\hline \multirow[t]{2}{*}{ Bhmt2 } & C & rs264842124 & $\mathrm{T}$ & downstream 500B \\
\hline & $\mathrm{T}$ & rs47046885 & C & 3'-UTR \\
\hline \multirow[t]{5}{*}{ Mthfr } & $A$ & $148039163^{a}$ & $\mathrm{G}^{*}$ & unknown \\
\hline & $G$ & $148039229^{a}$ & $\mathrm{C}^{*}$ & \\
\hline & C & $148039557^{a}$ & $G$ & \\
\hline & C & $148040119^{a}$ & $\mathrm{~T}$ & \\
\hline & $\mathrm{C}$ & $148040240^{a}$ & $\mathrm{~T}$ & \\
\hline \multirow[t]{4}{*}{ Mtrr } & $T$ & rs108123629 & t/a & 3'-UTR \\
\hline & C & rs108647820 & $\mathrm{c} / \mathrm{a}$ & 3'-UTR \\
\hline & $G$ & rs108535269 & G & 3'-UTR \\
\hline & $T$ & rs108864771 & $\mathrm{T}$ & 3'-UTR \\
\hline \multirow[t]{9}{*}{ Shmt1 } & $A$ & rs26957199b & $\mathrm{G}^{*}$ & 3'-UTR \\
\hline & A & rs47721266 & $\mathrm{C}^{*}$ & downstream 500B \\
\hline & $A$ & rs49213375 & $\mathrm{C}^{*}$ & downstream 500B \\
\hline & $\mathrm{T}$ & rs222704054 & $\mathrm{C}^{*}$ & downstream 500B \\
\hline & A & rs222753876 & $\mathrm{G}^{*}$ & downstream 500B \\
\hline & $A$ & rs108000000 & $\mathrm{G}^{*}$ & downstream 500B \\
\hline & C & rs26957196 & $A^{*}$ & downstream 500B \\
\hline & $G$ & rs45981582 & $A^{*}$ & downstream 500B \\
\hline & G & rs26957195 & $A^{*}$ & downstream 500B \\
\hline \multirow[t]{6}{*}{ Shmt2 } & $G$ & rs252755979 & $T^{*}$ & 3'-UTR \\
\hline & C & rs240177349 & $T^{*}$ & 3'-UTR \\
\hline & C & rs51081486 & $T^{*}$ & 3'-UTR \\
\hline & $A$ & rs47587430 & $\mathrm{G}^{*}$ & 3'-UTR \\
\hline & C & rs260368105 & $\mathrm{T}^{*}$ & 3'-UTR \\
\hline & $G$ & rs49954613 & $\mathrm{C}^{*}$ & 3'-UTR \\
\hline
\end{tabular}

The table shows results of a search for SNPS in key genes of folate metabolism of CBA/J mice carried out in The Mouse Genome Project web page (http://www.sanger.ac.uk/science/data/mouse-genomes-project), where the C57BL76J strain is used as reference. *Multiple consequences, only the main one listed. a Number indicates position. ${ }^{b}$ Gene assignment differs between MGP and NCBI databases.

and evaluation of several SNPs that is out of the scope of the present article.

Despite the interest of a prolonged study to get deeper insight the interplay between Nutrition and cochlear aging, the continuity of this long-term nutritional treatment was precluded by the presence of megaloblastic anemia. This fact was described in previous studies analyzing low intakes of folate or vitamin $\mathrm{B}_{12}$ for extended periods of time (Cox et al., 1961; Bills et al., 1992), but was not evident in C57BL/6J mice after 2 months of diet (Martinez-Vega et al., 2015a). Altogether, 
our data support the role of folate deficiency in premature development of hearing loss, although new experiments aimed to analyze its impact in strains with delayed onset of this sensory impairment should consider beginning nutritional interventions at later stages of animal development. Moreover, studies on the putative value of folate supplementation against hearing loss are needed, as well as the analysis of the incidence of this sensory decline in human populations living in countries with mandatory folate fortification for which only preliminary data are available: http://www.cdc.gov/ncbddd/hearingloss/data.html. In this line, nutrigenomic studies may render clues about the interaction between folate deficiency and the cochlear genome.

\section{CONCLUSION}

The results presented herein reinforce the crucial role of folic acid status in the cochlea. Moreover, our data suggest that differences encountered in animal and human studies analyzing the interplay between nutritional deficiencies and hearing loss, especially in age-related hearing loss, may depend on the combinatory effects of both diet and genetic background.

\section{REFERENCES}

Aburto, M. R., Magariños, M., Leon, Y., Varela-Nieto, I., and SanchezCalderon, H. (2012). AKT signaling mediates IGF-I survival actions on otic neural progenitors. PLoS One 7:e30790. doi: 10.1371/journal.pone.00 30790

Attias, J., Raveh, E., Aizer-Dannon, A., Bloch-Mimouni, A., and Fattal-Valevski, A. (2012). Auditory system dysfunction due to infantile thiamine deficiency: long-term auditory sequelae. Audiol. Neurootol. 17, 309-320. doi: 10. $1159 / 000339356$

Bills, N. D., Koury, M. J., Clifford, A. J., and Dessypris, E. N. (1992). Ineffective hematopoiesis in folate-deficient mice. Blood 79, 2273-2280.

Cadoni, G., Agostino, S., Scipione, S., and Galli, J. (2004). Low serum folate levels: a risk factor for sudden sensorineural hearing loss? Acta Otolaryngol. 124, 608-611. doi: 10.1080/00016480410016216

Camarero, G., Avendano, C., Fernandez-Moreno, C., Villar, A., Contreras, J., de Pablo, F., et al. (2001). Delayed inner ear maturation and neuronal loss in postnatal Igf-1-deficient mice. J. Neurosci. 21, 7630-7641.

Cediel, R., Riquelme, R., Contreras, J., Diaz, A., and Varela-Nieto, I. (2006). Sensorineural hearing loss in insulin-like growth factor I-null mice: a new model of human deafness. Eur. J. Neurosci. 23, 587-590. doi: 10.1111/j.14609568.2005.04584.x

Cohen-Salmon, M., Regnault, B., Cayet, N., Caille, D., Demuth, K., Hardelin, J. P., et al. (2007). Connexin30 deficiency causes instrastrial fluid-blood barrier disruption within the cochlear stria vascularis. Proc. Natl. Acad. Sci. U S A 104, 6229-6234. doi: 10.1073/pnas.0605108104

Cox, E. V., Meynell, M. J., and Cooke, W. T. (1961). Folic acid deficiency. Postgrad. Med. J. 37, 252-256. doi: 10.1136/pgmj.37.427.252

Dror, A. A., and Avraham, K. B. (2009). Hearing loss: mechanisms revealed by genetics and cell biology. Annu. Rev. Genet. 43, 411-437. doi: 10.1146/annurevgenet-102108-134135

Durga, J., Anteunis, L. J., Schouten, E. G., Bots, M. L., Kok, F. J., and Verhoef, P. (2006). Association of folate with hearing is dependent on the 5,10methylenetetrahdyrofolate reductase $677 \mathrm{C} \rightarrow$ T mutation. Neurobiol. Aging 27, 482-489. doi: 10.1016/j.neurobiolaging.2005.03.002

Fusconi, M., Chistolini, A., de Virgilio, A., Greco, A., Massaro, F., Turchetta, R., et al. (2012). Sudden sensorineural hearing loss: a vascular cause? Analysis of prothrombotic risk factors in head and neck. Int. J. Audiol. 51, 800-805. doi: 10. 3109/14992027.2012.705904

\section{AUTHOR CONTRIBUTIONS}

RM-V carried out animal experimentation, histological evaluation and statistical analyses; RM-V and SM-C performed hearing assessment; TP and GV-M performed metabolite analysis; IV-N, GV-M and MAP conceived, designed and coordinated the study; MAP drafted the manuscript. All authors gave final approval for publication.

\section{FUNDING}

RM-V was a fellow of the JAE-CSIC predoctoral program. This work was supported by grants of the Ministerio de Economía y Competitividad (SAF2014-53979-R to IV-N; BFU2009-08977 to MAP), the European Union (FP7-AFHELO and TARGEAR to IV-N).

\section{ACKNOWLEDGMENTS}

The authors wish to thank the Genomics and Non-invasive Neurofunctional Evaluation facilities (IIBM, CSIC-UAM) for technical support.

Horne, D. W., and Patterson, D. (1988). Lactobacillus casei microbiological assay of folic acid derivatives in 96-well microtiter plates. Clin. Chem. 34, 2357-2359.

Houston, D. K., Johnson, M. A., Nozza, R. J., Gunter, E. W., Shea, K. J., Cutler, G. M., et al. (1999). Age-related hearing loss, vitamin B-12 and folate in elderly women. Am. J. Clin. Nutr. 69, 564-571.

Karli, R., Gül, A., and Uğur, B. (2013). Effect of vitamin B12 deficiency on otoacoustic emissions. Acta Otorhinolaryngol. Ital. 33, 243-247.

Keane, T. M., Goodstadt, L., Danecek, P., White, M. A., Wong, K., Yalcin, B., et al. (2011). Mouse genomic variation and its effect on phenotypes and gene regulation. Nature 477, 289-294. doi: 10.1038/nature10413

Kundu, S., Munjal, C., Tyagi, N., Sen, U., Tyagi, A. C., and Tyagi, S. C. (2012). Folic acid improves inner ear vascularization in hyperhomocysteinemic mice. Hear. Res. 284, 42-51. doi: 10.1016/j.heares.2011.12.006

Lasisi, A. O., Fehintola, F. A., and Yusuf, O. B. (2010). Age-related hearing loss, vitamin B12 and folate in the elderly. Otolaryngol. Head Neck Surg. 143 826-830. doi: 10.1016/j.otohns.2010.08.031

Li, H. S., and Borg, E. (1991). Age-related loss of auditory sensitivity in two mouse genotypes. Acta Otolaryngol. 111, 827-834. doi: 10.3109/00016489109138418

Liu, H. H., Lu, P., Guo, Y., Farrell, E., Zhang, X., Zheng, M., et al. (2010). An integrative genomic analysis identifies Bhmt2 as a diet-dependent genetic factor protecting against acetaminophen-induced liver toxicity. Genome Res. 20, 28-35. doi: 10.1101/gr.097212.109

Martinez-Vega, R., Garrido, F., Partearroyo, T., Cediel, R., Zeisel, S. H., MartínezÁlvarez, C., et al. (2015a). Folic acid deficiency induces premature hearing loss through mechanisms involving cochlear oxidative stress and impairment of homocysteine metabolism. FASEB J. 29, 418-432. doi: 10.1096/fj.14-259283

Martinez-Vega, R., Partearroyo, T., Vallecillo, N., Varela-Moreiras, G., Pajares, M. A., and Varela-Nieto, I. (2015b). Long-term omega-3 fatty acid supplementation prevents expression changes in cochlear homocysteine metabolism and ameliorates progressive hearing loss in C57BL/6J mice. J. Nutr. Biochem. 26, 1424-1433. doi: 10.1016/j.jnutbio.2015.07.011

Müller, M., von Hünerbein, K., Hoidis, S., and Smolders, J. W. (2005). A physiological place-frequency map of the cochlea in the CBA/J mouse. Hear Res. 202, 63-73. doi: 10.1016/j.heares.2004.08.011

Murillo-Cuesta, S., Camarero, G., González-Rodriguez, A., De La Rosa, L. R., Burks, D. J., Avendaño, C., et al. (2012). Insulin receptor substrate 2 (IRS2)deficient mice show sensorineural hearing loss that is delayed by concomitant protein tyrosine phosphatase 1B (PTP1B) loss of function. Mol. Med. 18, 260-269. doi: 10.2119/molmed.2011.00328 
Pajares, M. A., and Pérez-Sala, D. (2006). Betaine homocysteine S-methyltransferase: just a regulator of homocysteine metabolism? Cell Mol. Life Sci. 63, 2792-2803. doi: 10.1007/s00018-006-6249-6

Reagan, W. J., Irizarry-Rovira, A., Poitout-Belissent, F., Bolliger, A. P., Ramaiah, S. K., Travlos, G., et al. (2011). Best practices for evaluation of bone marrow in nonclinical toxicity studies. Vet. Clin. Pathol. 40, 119-134. doi: 10. 1111/j.1939-165x.2011.00323.x

Rodriguez-de la Rosa, L., López-Herradón, A., Portal-Núñez, S., MurilloCuesta, S., Lozano, D., Cediel, R., et al. (2014). Treatment with N- and Cterminal peptides of parathyroid hormone-related protein partly compensate the skeletal abnormalities in IGF-I deficient mice. PLoS One 9:e87536. doi: 10. 1371/journal.pone.0087536

Roth, T. N., Hanebuth, D., and Probst, R. (2011). Prevalence of age-related hearing loss in Europe: a review. Eur. Arch. Otorhinolaryngol. 268, 1101-1107. doi: 10. 1007/s00405-011-1597-8

Sanchez-Calderon, H., Rodriguez-de la Rosa, L., Milo, M., Pichel, J. G., Holley, M., and Varela-Nieto, I. (2010). RNA microarray analysis in prenatal mouse cochlea reveals novel IGF-I target genes: implication of MEF2 and FOXM1 transcription factors. PLoS One 5:e8699. doi: 10.1371/journal.pone. 0008699

Tamura, T. (1990). "Microbiological assays of folates," in Folic Acid Metabolism in Health and Disease, eds M. F. Piccairo R. Stokstad and J. F. Gregory (New York, NY: Wiley-Liss, Inc.), 121-137.
Uchida, Y., Sugiura, S., Ando, F., Nakashima, T., and Shimokata, H. (2011) Hearing impairment risk and interaction of folate metabolism related gene polymorphisms in an aging study. BMC Med. Genet. 12:35. doi: 10.1186/14712350-12-35

Willott, J. F., Erway, L. C., Archer, J. R., and Harrison, D. E. (1995). Genetics of age-related hearing loss in mice. II. Strain differences and effects of caloric restriction on cochlear pathology and evoked response thresholds. Hear. Res. 88, 143-155. doi: 10.1016/0378-5955(95)00107-f

Zheng, Q. Y., Johnson, K. R., and Erway, L. C. (1999). Assessment of hearing in 80 inbred strains of mice by ABR threshold analyses. Hear. Res. 130, 94-107. doi: 10.1016/s0378-5955(99)00003-9

Conflict of Interest Statement: The authors declare that the research was conducted in the absence of any commercial or financial relationships that could be construed as a potential conflict of interest.

Copyright (c) 2016 Martínez-Vega, Murillo-Cuesta, Partearroyo, Varela-Moreiras, Varela-Nieto and Pajares. This is an open-access article distributed under the terms of the Creative Commons Attribution License (CC BY). The use, distribution and reproduction in other forums is permitted, provided the original author(s) or licensor are credited and that the original publication in this journal is cited, in accordance with accepted academic practice. No use, distribution or reproduction is permitted which does not comply with these terms. 